\title{
Characteristics of Masonry Blocks Manufactured with Rice Husk Ash (RHA) and Lime
}

\author{
B.H.J. Pushpakumara and G.H.M.J. Subashi De Silva
}

\begin{abstract}
Rice husk is one of major agro-waste material in Sri Lanka. Rice Husk Ash (RHA) is produced by burning Rice husk as fuel in brick kiln. Rice husk ash produced by burning at high temperature contains pozzolanic constituents. In Sri Lanka, cement is extensively used to manufacture masonry blocks, although the cost of cement is high. Because of having highly pozzolanic constituents in RHA, it can be used as a building material, instead of cement, to produce cement sand masonry blocks.
\end{abstract}

It was frequently reported that compressive strength of RHA based blocks increases with increasing the RHA content up to 5\% and further addition of RHA causes to decrease in compressive strength. In this study, an attempt is made to increase the utilization of RHA by adding $\mathrm{Ca}^{2+}$ to the mixture. Solid masonry blocks, having the size of $360 \mathrm{~mm} \times 100 \mathrm{~mm} \times 170 \mathrm{~mm}$, were cast with the mix proportion of 1:6 Cement - Sand. Blocks were manufactured in two series. In the first series, RHA was used as addition with respect to weight of cement. In this series, four different RHA contents (i.e., $0 \%, 5 \%$, $10 \%$, and $15 \%$ ) were used with constant lime content $(10 \%)$. In the second series, RHA was used as partial replacement for cement with four different RHA contents (i.e., 5\%, 10\%, 15\% and 20\%) with constant lime content (10\%).The blocks were tested for 7, 14 and 28 Day compressive strength. With the presence of lime (10\%), the optimum 28 Day compressive strength was found at the level of $10 \%$ RHA. When RHA was used as addition, the optimum 28 Day average compressive strength of block was found as $4.937 \mathrm{~N} / \mathrm{mm}^{2}$. When RHA was used as partial replacement for cement, 28 Day average compressive strength of block was found as $3.467 \mathrm{~N} / \mathrm{mm}^{2}$. Thermal performances of the RHA lime based blocks were also investigated. It was found that thermal conductivity of RHA lime based block was lower compared with that of the conventional block. The RHA lime based blocks showed better structural and thermal performances. Increased use of RHA will reduce the unit cost of masonry block while improving sustainability.

Keywords: Rice Husk Ash (RHA), pozzolanic constituents, cement masonry blocks, compressive strength, thermal performance

\section{Introduction}

Main occupation of Sri Lankans has been agriculture since of ancient times. As a result, rice production is being increased. Rice milling industry generates a lot of rice husk during milling of paddy, which comes from the fields. During milling of paddy, about $72 \%$ of the weight of the paddy is received as rice, $5 \%-8 \%$ of broken rice and bran. About $20 \%-22 \%$ of the weight of paddy is received as husk (Muthadhi et al. [8]). This husk contains about $75 \%$ organic volatile matter and the balance $25 \%$ of the weight of this husk is converted into ash during the firing process. This is known as Rice Husk Ash (RHA) (Agus [1]).

A mixture of sand, cement and water is extensively used to manufacture masonry blocks in Sri Lanka, although the cost of cement is high. Attempts have been made by previous researchers (e.g. Alireza et al. [2], Dolage et al.
[6], Ghassan et al. [7], Nilantha et al. [9]) and Oyekan et al. [10]) to investigate properties of different materials that can be used as replacement for cement in civil engineering construction field.

Rice Husk Ash has been included in several studies because of its highly pozzolanic constituents that can be used as a partial replacement material for cement to produce cement sand masonry blocks (Ghassan et al. [7], Nilantha et al. [9] and Oyekan et al. [10]).

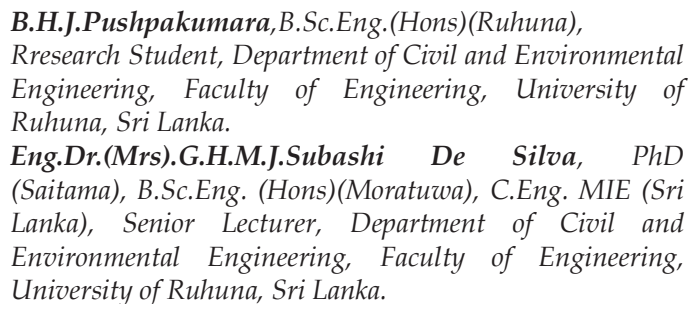


Chemical composition of RHA that are available in different countries has been studied by different researchers in their previous studies (Agus [1], Ghassan et al. [7] and Nilantha et al. [9]). Nilantha et al. [9] has reported the properties of the Sri Lankan RHA, which was collected from a brick kiln. Agus [1] and Ghassan et al. [7] have investigated the properties of RHA obtained from control burning process. Chemical compositions of RHA reported in above mentioned studies are compared in Table 1.

Table 1- Comparison of Chemical Composition of RHA (Wt. \%)

\begin{tabular}{|c|c|c|c|}
\hline & $\begin{array}{c}\text { Nilantha } \\
\text { et al. [9] }\end{array}$ & $\begin{array}{c}\text { Ghassan } \\
\text { et al.[7] }\end{array}$ & Agus [1] \\
\hline $\mathrm{SiO}_{2}$ & 91.75 & 88.32 & 89.08 \\
\hline $\mathrm{Al}_{2} \mathrm{O}_{3}$ & 2.07 & 0.46 & 1.75 \\
\hline $\mathrm{Fe}_{2} \mathrm{O}_{3}$ & 1.56 & 0.67 & 0.78 \\
\hline $\mathrm{CaO}$ & 1.3 & 0.67 & 1.29 \\
\hline $\mathrm{MgO}$ & 1 & 0.44 & 0.64 \\
\hline $\mathrm{Na}_{2} \mathrm{O}$ & 0 & - & 0.85 \\
\hline $\mathrm{K}_{2} \mathrm{O}$ & 2.32 & 2.91 & 1.38 \\
\hline $\begin{array}{c}\text { Loss in } \\
\text { ignition }\end{array}$ & - & 5.81 & 2.05 \\
\hline
\end{tabular}

Generally, a similar chemical composition of RHA can be observed. RHA contains around $88 \%-92 \%$ amorphous silica (i.e. $\mathrm{SiO}_{2}$ ). In the conversion of rice husks into ash, the combustion process removes the organic matter and leaves the silica rich residue. Rice husks are approximately cellulose $(40 \%-45 \%)$, lignin $(25 \%-30 \%)$, ash $(15 \%-20 \%)$ and moisture $(8 \%-$ $15 \%$ ) (Agus [1]). To reduce the amount of waste materials, rice husks are incinerated by controlled combustion to remove the lignin and cellulose, leaving behind an ash composed mostly of silica (retaining $25 \%$ of the mass of rice husks) (Agus [1]).

During the controlled burning process, the carbon content is burnt off and all that remains is the silica content. If rice husk was burnt in an uncontrolled manner RHA is less reactive (De Silva and Uduweriya [5], Dolage et al. [6] and Oyekan et al. [10]). The silica must be kept at a non-crystalline state in order to produce an ash with high pozzalonic activity. It has frequently been reported that the ideal temperature for producing such results is between $500{ }^{\circ} \mathrm{C}$ and $700{ }^{\circ} \mathrm{C}$ (De Silva and Uduweriya [5], Ghassan et al. [7] and Semasinghe et al. [12]). Rice husk burnt as fuel in brick kiln can also have pozzalonic activity as the burning process usually occurred at an increased temperature and the produced RHA shows chemical compositions similar to the composition of RHA obtained from controller burning process (Table 1). In brick kiln, where the rice husks were burnt, the temperature varies from $550{ }^{\circ} \mathrm{C}$ to $750{ }^{\circ} \mathrm{C}$ (De Silva and Uduweriya [5]).

By adding pozzolanic material to mortar or concrete mix, the pozzolanic reaction starts when $\mathrm{Ca}(\mathrm{OH})_{2}$ is released. Generated $\mathrm{Ca}(\mathrm{OH})_{2}$ are dissolved in the water and produce $\mathrm{Ca}^{2+}$ and $\mathrm{OH}^{-}$ions. The $\mathrm{pH}$ value of the mixture increases because of the hydration of cement. The $\mathrm{Ca}^{2+}$ and $\mathrm{OH}^{-}$react with $\mathrm{SiO}_{2}$ and $\mathrm{Al}_{2} \mathrm{O}_{3}$ and produce secondary cementitious products called "Tobermorite gel" (Calcium Silicate Hydrate(C-S-H) and Calcium Aluminates Hydrate(C-A-H)) that give strength to the cement paste. Previous researches have revealed that $\mathrm{Ca}^{2+}$ in the cement reacts with the silica in the RHA in the presence of moisture (Oyekan et al. [10]). These "Tobermorite" particles are responsible for important engineering properties such as compressive strength.

In previous studies, it was found that 28 Day compressive srength has developed with partial replacement of cement by RHA (i.e., at 5\% cement was replaced by RHA) compared to $0 \%$ RHA (Nilantha et al. [9] and Oyekan et al. [10]). It can be expected that in the presence of moisture, the $\mathrm{Ca}^{2+}$ in the cement reacts with the silica in RHA and produces "Tobermorite gel", which will be responsible for the strength gain of the paste. The increase of quantity of RHA decreases the compressive strength of the cement sand blocks as reported in the pervious studies (Nilantha et al. [9] and Oyekan et al. [10]). This may be due to lack of $\mathrm{Ca}^{2+}$ in the cement to react with the silicate in RHA.

When constructing buildings, blocks play a major role by fulfilling some conventional properties of blocks such as compressive strength, water absorption, and thermal performance. In using blocks for walls, water absorption ability of blocks must be considered, because walls must have water resistance during the humid climate and rainy periods to minimize penetration of moisture or rain water into the inside of the building. When constructing a wall, burnt blocks should be immersed in water to absorb water, otherwise the water, which is in the mortar will be absorbed by the blocks and then the mortar layer will not be properly strengthened. Therefore, blocks must have water absorption 
ability during the construction stage. After the construction, there should be a water resisting property through the blocks that will prevent penetration of rain water inside to the walls.

Consideration of thermal performance of the cement sand block is very important because thermally comfortable environment is required for any type of buildings. Thermal comfort is very important to many work-related factors. Considering workers in the industry, it can affect the level of distraction of the workers, and in turn affect their performance and productivity. To achieve a satisfactory thermal comfort level in most of the places air conditioning systems and fan systems are used. This increases energy consumption and creates an additional cost for operating the buildings. It would be profitable to use thermally insulating material for constructing walls while utilizing waste material for environmental friendly manner, such as RHA.

Objectives of the present study are;

- to investigate potential use of Rice Husk Ash (RHA) with lime to manufacture masonry blocks and

- to investigate compressive strength, water absorption and thermal performance of the block manufactured with RHA and lime.

It was hypothesized that $\mathrm{Ca}^{2+}$ that was added to the mixture would react with silicate in RHA and would produce secondary cementitious product, which would contribute to strength properties of the block. It was also hypothesized that adding of the $\mathrm{Ca}^{2+}$ to the mixture, would have an effect on quantity of RHA that could be effectively used in the mixture. By adding hydrated lime, amount of $\mathrm{Ca}^{2+}$ could be increased. The amount of $\mathrm{Ca}^{2+}$ added to the mixture, and silica, available in RHA, were satisfied to form "Tobermorite gel", which would give the strength to the cement block.

\section{Methodology}

Methodology includes selection of materials, manufacturing of masonry blocks with RHA and lime, and laboratory experiments.

\section{$2.1 \quad$ Materials}

Rice Husk Ash: Rice Husk Ash (RHA) was supplied from a brick kiln (Figure 1a) operating at Karapitiya, Galle. In this kiln, rice husk was burnt at an increased temperature and was the only material that was used as the fuel for the brick burning. The RHA collected from the kiln was free from any debris and consisted particles of different sizes (Figure 1b). The particle size of the RHA selected for the study was between $75 \mu \mathrm{m}$ and $150 \mu \mathrm{m}$. RHA was sieved through $150 \mu \mathrm{m}$ sieve pan and was collected the retained portion on $75 \mu \mathrm{m}$ sieve pan. The sieved RHA that was prepared for block manufacturing is shown in Figure 1c.

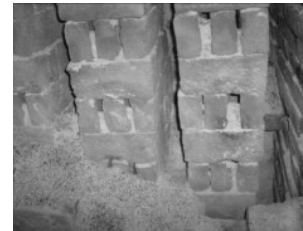

Figure 1aBrick Kiln

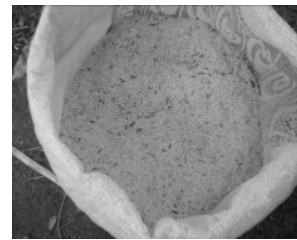

Figure 1b - RHA

collected from brick kiln

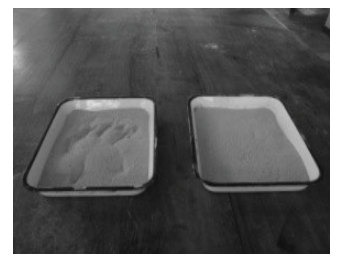

Figure 1c - Sieved RHA

Sand: The clean, sharp river sand was used in the study. The sand was free from clay, loam, dirt and any organic or chemical matters. The sand passing through $3 \mathrm{~mm}$ zone of British Standard test sieves as described in Sri Lanka Standard 855: 1989[13] was used.

Cement: The cement used in the study was Ordinary Portland Cement (OPC) as described in Sri Lanka Standard 855: 1989[13].

Water: Fresh, colourless, odourless and tasteless potable water that was collected from the pipe borne water of National Water Supply and Drainage Board (NWS\&DB) was used. Water was free from organic matters of any type as described in Sri Lanka Standard 855: 1989[13].

Lime: Hydrated lime available in the market (Figure 2) was used for block manufacturing work.

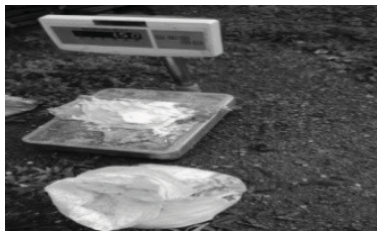

Figure 2 - Measuring Hydrated Lime 
With different amounts of RHA and a constant amount of lime, the RHA based cement sand blocks were manufactured in two series. In the first series, similar to the previous study by Nilantha et al. [9], RHA was used as addition with respect to weight of cement. Four different RHA contents (i.e., $0 \%, 5 \%, 10 \%$, and $15 \%$ ) with constant lime amount $(10 \%)$ were used. In the second series, RHA was used as partial replacement for cement with respect to the weight of cement. In this series, four different RHA contents (i.e., $5 \%, 10 \%, 15 \%$ and $20 \%$ ) with constant lime amount $(10 \%)$ were used.

Solid masonry blocks having the size of 360 $\mathrm{mm} \times 100 \mathrm{~mm} \times 170 \mathrm{~mm}$ were cast with mix proportion of 1:6 (Cement: Sand) by using local block manufacturing machine. Predetermined material quantities were measured by using weighing balance (Figure 2). In order to prepare mortar, the cement and RHA were thoroughly mixed and then the mixture was turned over number of times with the sand until an even colour and consistency were observed (Figure 3a). Measured quantity of hydrated lime was added to known volume of water. The water was mixed well to prepare uniform solvent (Figure 3b). The solution was filtered through a well cleaned piece of cloth. Then the solution was added to the mixture (Figure 3c). The mixture was further turned with a shovel until a mix of a sufficient workability was achieved. As RHA particles absorb more water, the water cement ratio was maintained at 0.7 .

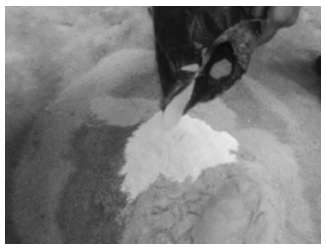

Figure 3a - Mixing

Cement Sand and RHA

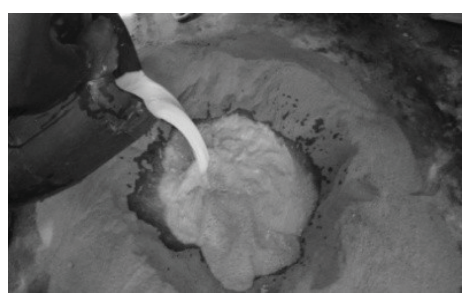

Figure 3c - Adding Lime Water Solvent to Mixture
The mortar was transferred to full height (i.e., $170 \mathrm{~mm}$ ) of the steel mould attached to the block manufacturing machine (Figure 4a) and vibro-compaction was performed on the mould for a period of 10 seconds, in order to have a proper compaction. After the first compaction, the mortar level reduced by $20 \%$ of the height of the mould. Then an additional amount of mortar was added to the mould and excess mortar was removed to get smooth surface. Vibro-compaction was performed for another 10 seconds, so as to get further compaction. After removal of the block from the mould (Figure $4 b$ ), they were left on the ground.

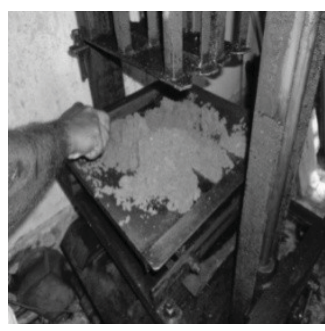

Figure 4a - Filling the Mould with Mortar

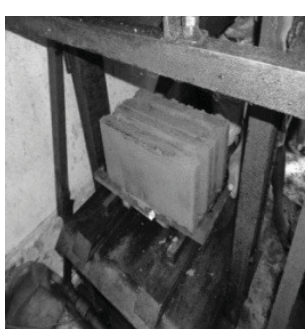

Manufactured Blocks
Figure $4 b$ -

\subsection{Curing of Blocks}

Twenty four hours after the manufacturing of blocks, curing was commenced and continued until the testing day. Curing process was identified as the most important part of the exercise, because the strength gained by the blocks depends upon the curing of the blocks. Blocks were cured by spraying normal water onto the blocks twice a day, by using a bucket.

\section{$2.4 \quad$ Laboratory Experiments}

\subsubsection{Compressive Strength}

The compressive strength was experimentally investigated by using the concrete crushing machine available in the Construction and Building Materials Laboratory (Figure 5). Three samples were tested for each addition and replacement level of RHA at the age of 7,14 and 28 days. Average compressive strength, at each age of the blocks, was determined by averaging three corresponding strength measurements. The strength characteristics of RHA based cement sand blocks were compared with the minimum standard compressive strength value of cement sand block at 28 Day (i.e., $2.8 \mathrm{~N} / \mathrm{mm}^{2}$ ) published in BS 6073: Part 2: 1981[4]. 


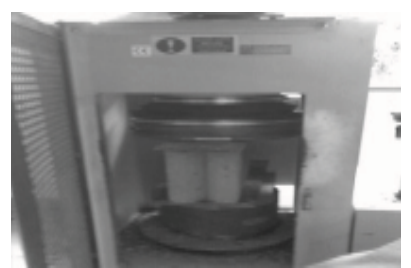

Figure 5 - Testing of Blocks using Concrete Crushing Machine

\subsubsection{Water Absorption}

Water absorption test was carried out to investigate the water absorption property of RHA lime based cement sand block, in which RHA was used as partial replacement for cement. Three samples of both cement sand blocks and RHA lime based cement sand blocks were used for the water absorption test. First, the samples were kept in an oven at a temperature of $100-105^{\circ} \mathrm{C}$ (Figure 6a), for a period of 24 hours and the dry weight of the blocks was measured. Then the same blocks were immersed in water for a period of 24 hours and the wet weight of blocks was measured. Water absorption was quantified as percentage of ratio of the reduction in weight to the dry weight of block. Water absorption of individual blocks was determined and the average value was calculated.

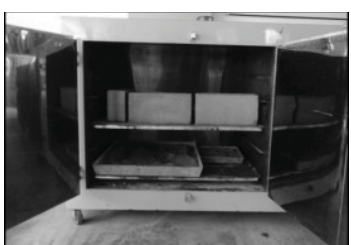

Figure 6a - Blocks in Oven

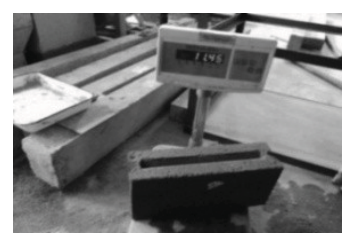

Figure $6 \mathrm{~b}$ Measuring Weight

\subsubsection{Thermal Performances}

Thermal performance was investigated and compared for two different blocks: one was RHA based cement sand block, which was manufactured with RHA as partial replacement for cement (i.e., $10 \%$ RHA) and the other one was a conventional block (i.e., 0\% RHA). The centre of the top surface (i.e., $360 \mathrm{~mm} \times 100 \mathrm{~mm}$ surface) of both blocks was drilled down to the middle of the depth of the blocks. All sides of the blocks, except two sides $(360 \mathrm{~mm} \times 170 \mathrm{~mm}$ sides), were covered by using polystyrene boards. These two surfaces, which were uncovered, received direct sun light.

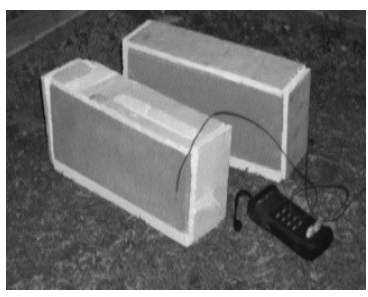

Figure 7 - Experiment set up for Measuring Temperature

The internal and surface temperatures of both blocks were measured by using a digital thermometer (MODEL 307) with 4-foot type " $\mathrm{K}$ " thermo couple (Figure 7). Measurements were taken from morning to midnight at 30 minutes interval in a sunny and a calm day of the month of August. The ambient temperature was also measured and recorded in the same time.

\section{Results}

\subsection{Particle Size Distribution for RHA}

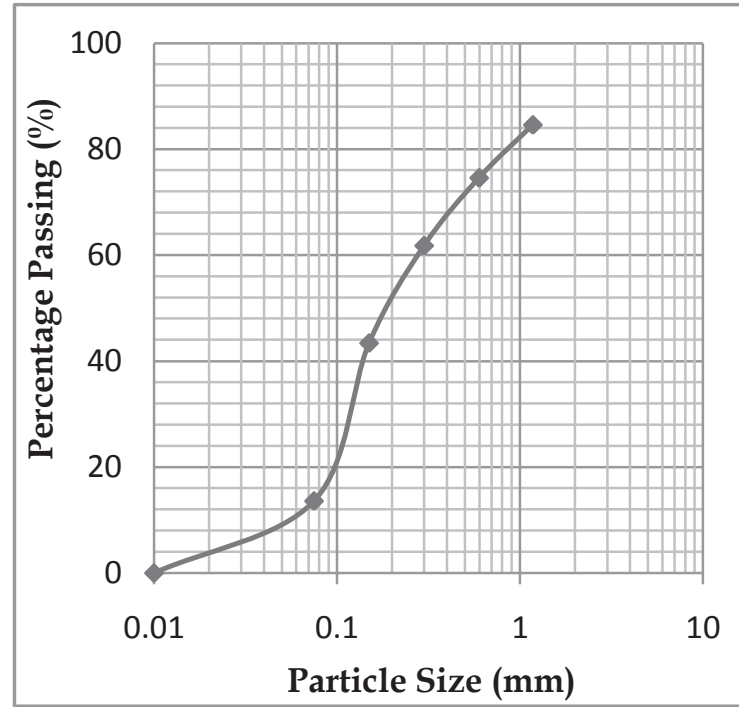

Figure 8 - Particle Size Distribution Curve for RHA Sample

Figure 8 shows the particle size distribution of RHA collected from the brick kiln. It can be seen from Figure 8 that the passing percentage through $150 \mu \mathrm{m}$ sieve is $43.4 \%$. The particle size of RHA material, which was used for the block manufacturing work in this study, is between $75 \mu \mathrm{m}$ and $150 \mu \mathrm{m}$ and there is a considerable amount of RHA in this range of particle size (Figure 8). 
The average compressive strength of RHA based cement sand blocks is shown in Table 2 . These blocks were manufactured with addition of different percentage of RHA and constant amount of lime ( $10 \%$ of cement weight).

Table 2 - Average Compressive Strength of Blocks (RHA was used as Addition)

\begin{tabular}{|c|c|c|c|c|c|}
\hline \multirow{2}{*}{ 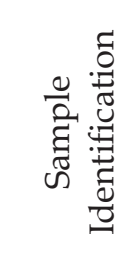 } & \multirow{2}{*}{ 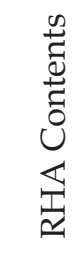 } & \multirow{2}{*}{ 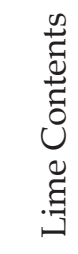 } & \multicolumn{3}{|c|}{$\begin{array}{c}\text { Average } \\
\text { Compressive } \\
\text { Strength }\left(\mathrm{N} / \mathrm{mm}^{2}\right)\end{array}$} \\
\hline & & & $\begin{array}{c}7 \\
\text { Day }\end{array}$ & $\begin{array}{c}14 \\
\text { Day }\end{array}$ & $\begin{array}{c}28 \\
\text { Day }\end{array}$ \\
\hline $\begin{array}{c}\text { Sample } \\
1\end{array}$ & $0 \%$ & $10 \%$ & 1.636 & 2.376 & 2.967 \\
\hline $\begin{array}{c}\text { Sample } \\
2\end{array}$ & $5 \%$ & $10 \%$ & 2.760 & 3.653 & 4.217 \\
\hline $\begin{array}{c}\text { Sample } \\
3 \\
\end{array}$ & $10 \%$ & $10 \%$ & 2.876 & 3.921 & 4.937 \\
\hline $\begin{array}{c}\text { Sample } \\
4\end{array}$ & $15 \%$ & $10 \%$ & 1.826 & 2.966 & 3.667 \\
\hline
\end{tabular}

It can be seen from Table 2 that the average compressive strength at 28 Day is greatest for Sample 3, for blocks which were produced with $10 \%$ RHA and $10 \%$ lime. However, 28 Day average compressive strength decreases with further addition of RHA (i.e., $15 \%$ ). The similar variation was observed with 7, 14 and 28 Day average compressive strength and can be clearly seen in Figure 9.

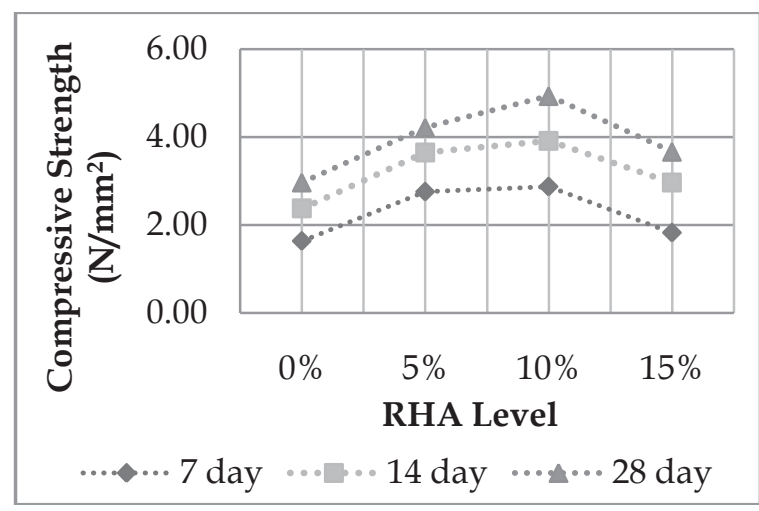

Figure 9 - Variation of Average Compressive Strength with \% of RHA (RHA was used as Addition)

Table 3 shows the average compressive strength of RHA based cement sand blocks for different RHA replacement level and addition of constant amount of lime $(10 \%$ of cement weight).
Table 3 - Average Compressive Strength of Blocks (RHA was used as Replacement for Cement)

\begin{tabular}{|c|c|c|c|c|c|}
\hline \multirow{2}{*}{ 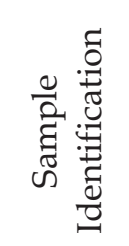 } & \multirow{2}{*}{ 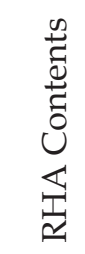 } & \multirow{2}{*}{ 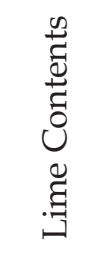 } & \multicolumn{3}{|c|}{$\begin{array}{c}\text { Average } \\
\text { Compressive } \\
\text { Strength }\left(\mathrm{N} / \mathrm{mm}^{2}\right)\end{array}$} \\
\hline & & & $\begin{array}{c}7 \\
\text { Day }\end{array}$ & $\begin{array}{c}14 \\
\text { Day }\end{array}$ & $\begin{array}{c}28 \\
\text { Day }\end{array}$ \\
\hline $\begin{array}{c}\text { Sample } \\
1 \\
\end{array}$ & $0 \%$ & $10 \%$ & 1.636 & 2.376 & 2.967 \\
\hline $\begin{array}{c}\text { Sample } \\
2 \\
\end{array}$ & $5 \%$ & $10 \%$ & 1.701 & 2.517 & 3.180 \\
\hline $\begin{array}{c}\text { Sample } \\
3 \\
\end{array}$ & $10 \%$ & $10 \%$ & 1.794 & 2.930 & 3.467 \\
\hline $\begin{array}{c}\text { Sample } \\
4 \\
\end{array}$ & $15 \%$ & $10 \%$ & 1.680 & 2.456 & 2.914 \\
\hline $\begin{array}{c}\text { Sample } \\
5\end{array}$ & $20 \%$ & $10 \%$ & 1.587 & 2.031 & 2.723 \\
\hline
\end{tabular}

It can be seen from Table 3 that optimum of the average compressive strength is observed at $10 \%$ of RHA replacement level (Sample 3) blocks, which were produced with 10\% RHA and 10\% lime. However, 28 Day average compressive strength decreases with increasing the RHA replacement level (i.e., $15 \%$ and $20 \%$ ) (Figure 10).

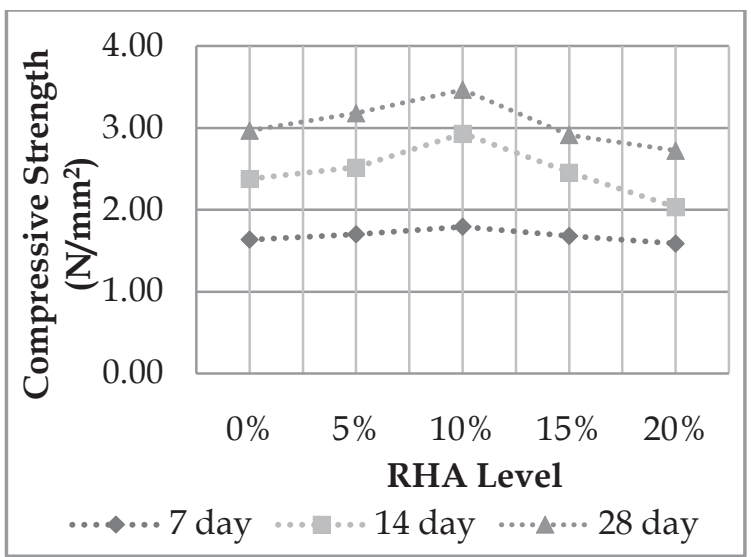

Figure 10 - Variation of Average Compressive Strength with the \% of RHA (RHA was used as Replacement for Cement)

The compressive strength test results show clearly that blocks, in which RHA was used as replacement for cement, satisfied the minimum standard value of $2.8 \mathrm{~N} / \mathrm{mm}^{2}$ according to BS6073: Part 2: 1981 [4]. The average compressive strength values were greater than the minimum requirement up to $15 \%$ RHA level. 
Table 4 presents the average water absorption of RHA based cement sand blocks.

Table 4 - Average Water Absorption (Presented as Percentage Values)

\begin{tabular}{|c|c|c|c|}
\hline 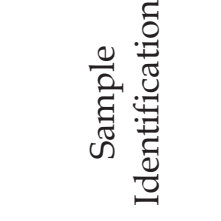 & 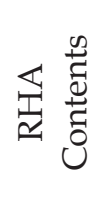 & . & $\begin{array}{c}\text { Average } \\
\text { Water } \\
\text { Absorption } \\
(\%)\end{array}$ \\
\hline $\begin{array}{c}\text { Conventional } \\
\text { Block }\end{array}$ & $0 \%$ & $0 \%$ & 13.987 \\
\hline Sample 1 & $0 \%$ & $10 \%$ & 15.210 \\
\hline Sample 2 & $5 \%$ & $10 \%$ & 19.149 \\
\hline Sample 3 & $10 \%$ & $10 \%$ & 19.896 \\
\hline Sample 4 & $15 \%$ & $10 \%$ & 20.547 \\
\hline Sample 5 & $20 \%$ & $10 \%$ & 20.757 \\
\hline
\end{tabular}

It can be seen from Table 4 that the average water absorption of blocks prepared by using Sample 1 (i.e., 0\% RHA with 10\% lime) is greater $(15.21 \%)$ compared with the water absorption of conventional block (13.987\%). This higher water absorption is attributed to addition of $10 \%$ of lime to the mixture. In addition, average water absorption tends to increase with the increase of RHA percentage used as replacement for cement, with $10 \%$ lime.

\subsection{Thermal Performances}

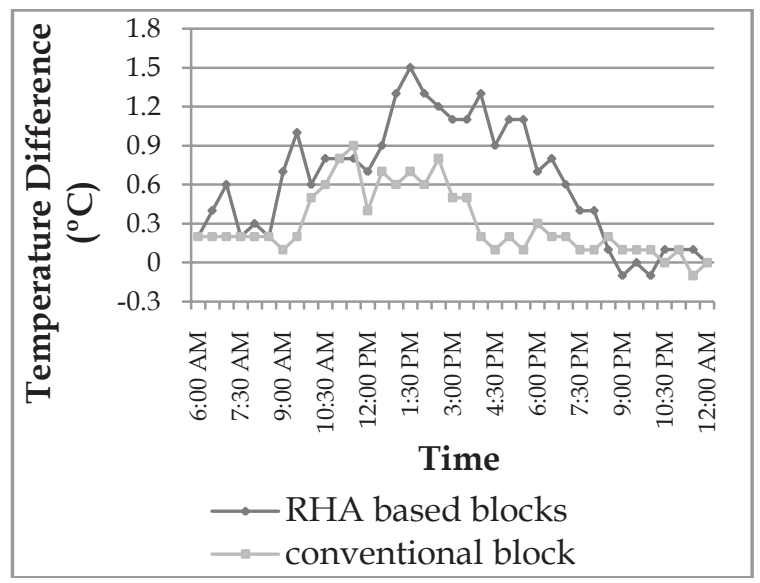

Figure 11 - Surplus Temperature (Outer Surface Temperature - Internal Temperature) Variation for Blocks

Figure 11 shows the variation of surplus temperature (i.e., difference in outer surface temperature and internal surface temperature) of RHA-lime based cement sand block and the conventional block. During the period of 9:00 am to $8: 30 \mathrm{pm}$, the surplus temperature of RHA based cement sand masonry block (10\% RHA replacement level for cement) is greater than that of the conventional block. From 8:30 p.m. to $12: 00$ mid night, the surplus temperature is not significantly different between two blocks. The surface temperatures of both blocks were almost the same. It seems, therefore, that the thermal conductivity of the RHA lime based block is lower than that of the conventional block.

\section{Discussion}

\subsection{Compressive Strength}

The compressive strength of the Rice Husk Ash (RHA) based cement - sand blocks obtained in the current study was compared with the compressive strength reported in the previous study, published by Nilantha et al. [9] (Figure 12). Direct comparison between these two studies is reasonable as both studies used the same particle size and the same RHA that was collected from brick kiln.

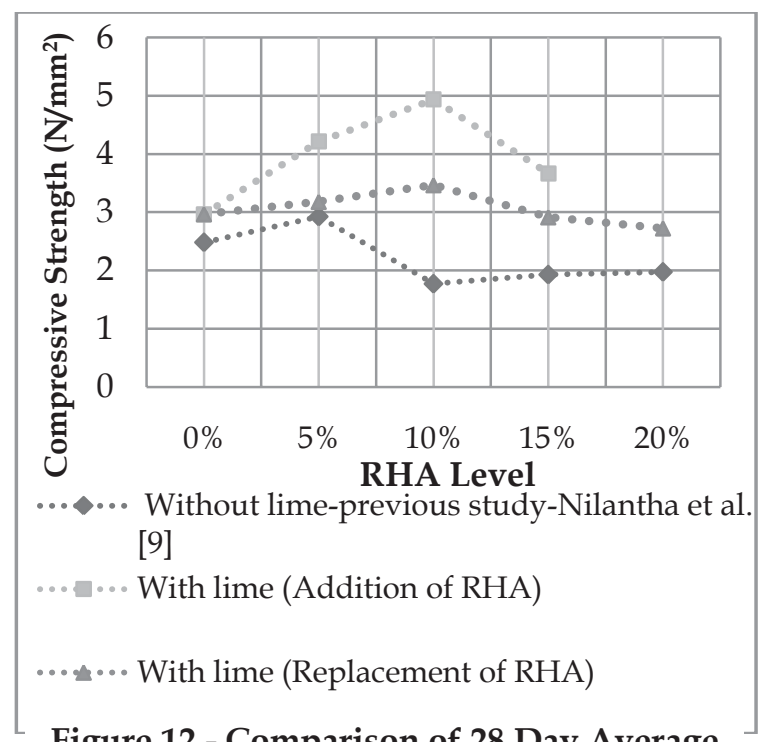

Figure 12 - Comparison of 28 Day Average Compressive Strength

Figure 12 indicates that the compressive strength of RHA based cement sand blocks increases with the addition of lime. In the previous study, it was found that compressive strength of RHA based cement sand blocks increased at 5\% RHA replacement level (Nilantha et al. [9]). They observed the 5\% development of the compressive strength comparing with minimum standard 
compressive strength value of cement sand block at 28 Day $\left(2.8 \mathrm{~N} / \mathrm{mm}^{2}\right)$ (BS 6073: Part 2: 1981) [4]. Increased strength might be due to pozzolanic reaction of RHA. Hydration of cement increases the $\mathrm{pH}$ value of water. $\mathrm{SiO}_{2}$ and $\mathrm{Al}_{2} \mathrm{O}_{3}$ in the mixture are dissolved due to increase of $\mathrm{pH}$ value. The hydrous Silica and Alumina react with the $\mathrm{Ca}^{2+}$ and produce insoluble compounds (CSH, CAH) often called as secondary cementitious products. Insoluble compounds tend to harden the mixture strongly than the normal condition. With the curing, this process is accelerated. This may contribute to increase the compressive strength of RHA based cement sand block at 5\% RHA content. The addition of RHA caused to decrease in compressive strength, because there might be a lack of $\mathrm{Ca}^{2+}$ for the continuation of reaction.

In the current study, with the addition of $\mathrm{Ca}^{2+}$ by using lime for the manufacturing of RHA based block, higher compressive strength has been achieved and also the optimum percentage of utilization of RHA has increased up to $10 \%$. It is the $76 \%$ development of the compressive strength compared with the minimum standard compressive strength value of cement sand block at 28 Day (i.e. 2.8 $\mathrm{N} / \mathrm{mm}^{2}$ ). At $15 \%$ of $\mathrm{RHA}$, the compressive strength is greater than the standard value. It is the $31 \%$ development of the compressive strength compared with the standard value (i.e., $2.8 \mathrm{~N} / \mathrm{mm}^{2}$ ). This is attributed to continuation of pozzolanic reaction of RHA with the $\mathrm{Ca}^{2+}$. The $\mathrm{Ca}^{2+}$ available in lime might contribute to increase the both compressive strength and amount of utilization of RHA. Increased $\mathrm{Ca}^{2+}$ reacts with more $\mathrm{SiO}_{2}$ available in the RHA, and increases the development of secondary cementitious products, which contribute to harden the cement paste.

The curing time also has effects on the compressive strength of blocks. The lime cementing process is a much slower reaction, which requires considerably longer time than the hydration of cement. The lime cementing process occurs well in hydrous environment. Therefore, with the continuation of curing process, there is a gain of compressive strength. In addition, the curing temperature accelerates the chemical reactions and solubility of the silicates thus increases the rate of strength gain. Moreover higher $\mathrm{pH}$ may accelerate formation of secondary cementitious products.
In the second step, the RHA was used as partial replacement for cement with constant amount of lime. The average 28 Day compressive strength of all samples (5\%, 10\%, 15\%and $20 \%$ of RHA) satisfied the minimum standard compressive strength value of cement sand block at 28 Day (i.e., $2.8 \mathrm{~N} / \mathrm{mm}^{2}$ ). By replacing $20 \%$ of RHA for cement with the addition of $10 \%$ lime, material cost for RHA lime based block is less than Rs 2.00 compared to material cost for the conventional cement-sand block. This calculation was performed based on the assumption that the cost of labour, energy and sand is same for both RHA lime based block and conventional block. RHA is a waste. It can be found near to the block construction area. Therefore, in collecting RHA there is no expenditure involved. However, for RHA lime based blocks, material cost for lime was less than the material cost for cement. With the rapid increase in the price of cement, the saving from material cost will be greater than Rs 2.00. For this calculation, the cost of cement bag (50 $\mathrm{kg}$ ) and lime (10 kg) were considered as Rs. 850.00 and Rs 180.00, respectively. Detailed calculations have been presented and discussed in Pushpakumara et al. [11].

\subsection{Water Absorption}

In the present study, the water absorption percentage of conventional block (i.e., $0 \%$ RHA and $0 \%$ lime) was similar to the water absorption of a similar block reported in the previous study: in the current study it was $13.987 \%$ while in the previous study, Nilantha et al. [9] it was $14.255 \%$. However, water absorption found in both studies was slightly greater than the recommended value, (i.e., 12\%) for masonry blocks according to BS 5628: Part 1: 2005[3]. Water absorption of the block, which has $0 \%$ RHA and $10 \%$ lime, was $15.21 \%$, implying that this block absorbs more water than that of conventional block. This slight increment might have occurred, because of the $10 \%$ of lime in the block. The block, which has 5\% RHA and 10\% lime, absorbs higher water amount $(19.149 \%)$ compared to that of the conventional block. This increment might have occurred, because of both lime $(10 \%)$ and RHA $(5 \%)$ content in the block.

According to the results obtained, water absorption increases with the percentage of RHA content (Table 4). The results showed the considerable water absorbent behaviour. This may be due to the rice husk ash: the porosity increases with addition of RHA. In the current 
study, the water absorption increases because of both lime and RHA in the block. Also as the RHA collected from brick kiln, it may consist with burnt clay particles. Although the amount of burnt clay particles might be very less, they would also absorb some amount of water. The comparison of water absorption properties between the current study and the previous study by Nilantha et al. [9] (Table 5) clearly shows that the adding of lime and increasing of RHA utilization causes to increase water absorption. This could also be decreased for some extent by selecting RHA without burnt brick particles.

Table 5: Comparison of Water Absorption Property with RHA Percentages (RHA was used as Replacement for Cement)

\begin{tabular}{|c|c|c|}
\hline \multirow{2}{*}{$\begin{array}{c}\text { Block } \\
\text { Identification }\end{array}$} & $\begin{array}{c}|c| \\
\text { Replacement } \\
\text { of RHA + } \\
\text { Lime (10\%) }\end{array}$ & $\begin{array}{l}\text { Replacement of } \\
\text { RHA-Nilantha } \\
\text { et al. [9] }\end{array}$ \\
\hline $\begin{array}{c}\text { Conventional } \\
\text { Block }\end{array}$ & 13.987 & 14.255 \\
\hline $0 \%$ RHA & 15.210 & 14.255 \\
\hline $5 \%$ RHA & 19.149 & 19.960 \\
\hline $10 \%$ RHA & 19.896 & 22.130 \\
\hline $15 \%$ RHA & 20.547 & 19.705 \\
\hline $20 \%$ RHA & 20.757 & - \\
\hline
\end{tabular}

\subsection{Thermal Performance}

$\mathrm{Ca}(\mathrm{OH})_{2}$ inherently available in the lime absorbs $\mathrm{CO}_{2}$ from air and produces $\mathrm{CaCO}_{3}$ $\left(\mathrm{CO}_{2}\right.$ is a refrigerant air and it helps to keep the lower temperature inside the block). Because of both lime and RHA, the colour of RHA lime based block is whiter than the conventional block. The $\mathrm{CaCO}_{3}$ provides whiter colour for the RHA lime based blocks. Therefore, the reflection of sun rays is much higher in the RHA lime based blocks than the conventional block. This might have also helped to reduce the internal temperature of RHA lime based blocks. In addition, RHA lime based blocks have lower thermal conductivity performances compared with the conventional blocks $(0 \%$ RHA blocks). Although in the current study, the maximum variation of temperature between the two blocks (i.e., RHA lime based block and conventional block) is around $1.2{ }^{\circ} \mathrm{C}$, greater temperature variation between the two blocks can be expected in real application of blocks as wall material. When blocks are used as wall material, heat transmission length would be twice of the transmission length of the current study. Nilantha et al. [9], stated that maximum temperature difference between two model houses (model houses made by using $5 \%$ of RHA replacement and conventional blocks) was $2^{\circ} \mathrm{C}$ and this was experienced at 1.00 p.m. RHA lime based blocks may provide more thermally comfortable environment compared with conventional blocks, implying that RHA based blocks will reduce the operating cost for energy of buildings.

The Rice Husk Ash sample collected from brick kiln contains $43.4 \%$ amount of fine particles (i.e., particle size smaller than $150 \mu \mathrm{m}$ ). Therefore, RHA for manufacturing of blocks can be found easily from brick kiln. RHA used for brick manufacturing showed better performances with the addition of $\mathrm{Ca}^{2+}$, in particular higher compressive strength and greater utilization of RHA. Further, blocks manufactured with RHA and lime caused to have less heat transmission through the block. The RHA can be effectively used in block manufacturing, resulting to prevent environmental pollution caused by open dumping of RHA. In addition, utilisation of RHA for replacing cement will reduce the $\mathrm{CO}_{2}$ emission from cement production. The cost of cement is rapidly increasing. Therefore, alternative materials that can be used to reduce the usage of cement are essential. The RHA with lime gives good cementitious product and shows excellent strength gain. Use of locally available waste, RHA, as an alternative material for cement would reduce the embodied energy to appreciably low levels. Reducing the embodied energy of a product helps to save the energy that is consumed during the production processes and utility processes, and reduce the carbon emission during production and utility period.

\section{Conclusions}

The Rice Husk Ash (RHA) wasted from brick kiln is pozzolanic and found as suitable to use in manufacturing masonry blocks. Addition of $\mathrm{Ca}^{2+}$ resulted in increasing the utilization of RHA amount and increased the compressive strength compared to adding of RHA without lime. RHA lime based cement sand blocks have greater compressive strength and can be used for load bearing walls as well. The replacement of RHA also shows higher compressive strength compared to the standard requirements. Thermal conductivity of RHA 
based blocks is a lower value compared to the blocks without RHA. These blocks save material cost and help to utilize the rice husk ash waste. Utilization of RHA for block manufacturing prevents environmental pollution caused by open dumping of rice husk ash and reduces $\mathrm{CO}_{2}$ emission from cement production.

\section{Acknowledgement}

The authors wish to express their special thanks to Faculty of Engineering, University of Ruhuna for providing necessary funds and assistance in carrying out research work presented in this paper.

\section{References}

1. Agus S.M., "Utilization of Uncontrolled Burnt Rice Husk Ash in Soil Improvement", Dimensi Teknik Sipil, Vol.4 (2) September 2002, pp.100105

2. Alireza N. G., Suraya A. R., Farah Nora A. Aziz and Mohamad A. M.S., "Contribution of Rice Husk Ash to the Properties of Mortar and Concrete: A review", Journal of American Science, 2010; 6(3), pp.157-165

3. British Standard 5628-Part 1: 2005 Code of practice for the use of masonry. Structural use of unreinforced masonry

4. British Standard 6073-Part 2: 1981 Precast Concrete Masonry Units. Method for Specifying Precast Masonry Units.

5. De Silva $S$ and Uduweriya R.B.Y.B., "Investigation of the Properties of Concrete Containing Rice-Husk-Ash" Transactions of the Institution of Engineers, Sri Lanka, 2011, pp. 7179.

6. Dolage D.A.R., Mylvaganam K., Mayoorathan P. and Inparatnam S. , "Use of Rice Husk Ash Blended Cement to Produce Cement Sand Blocks: Optimal Level of Cement Replacement for Compressive Strength", Engineer-Journal of the Institution of Engineers, Sri Lanka, ISSN18001122 Vol. XXXXIV,No.02, April 2011,pp.11-19

7. Ghassan A.H., Mahmud H.B. "Study on Properties of Rice Husk Ash and Its Use as Cement Replacement Material", Materials Research, 2010; 13(2), pp185-190

8. Muthadhi A. and Kothandaraman S., "Optimum Production Conditions for Reactive Rice Husk Ash", Materials and Structures, 2010; 43, pp.1303-1315
9. Nilantha B.G.P., Jiffry I., Kumara Y.S. and Subashi G.H.M.J., "Structural and Thermal Performances of Rice Husk Ash (RHA) Based Sand Cement Block", Proceeding of the International Conference on Sustainable Built Environments (ICSBE), Sri Lanka, December 2010, pp.138-144.

10. Oyekan G.L. and Kamiyo O.M., "Effect of Nigerian Rice Husk Ash on some Engineering properties of Sandcrete Blocks and Concrete", Research Journal of Applied Sciences, 2008; 3 (5), pp.345-351

11. Pushpakumara B.H.J., Kapukotuwa S.B.K.D.K. and Samarasignhe B.G.C.M., "Effect of Lime on Characteristics of Rice Husk Ash (RHA) Based Masonry Blocks", Undergraduate Research Report, Faculty of Engineering, University of Ruhuna, 2011

12. Semasinghe E.M.C.N., Senevirathna P.A.A.U., Seneviratne S.M.H.B. and Abeyruwan H., "Effects of Biomass Based Pozzolanic Material on Chloride Ion Penetration in Concrete" Transactions of the Institution of Engineers, Sri Lanka, 2011, pp.80-86.

13. Sri Lanka Standard 855: 1989, Specification for Cement Blocks. 